ESTUdios INTERNACIONALES I70 (20II) - ISSN O7I6-0240 • 55-79

\title{
De la estrategia del encanto a la potencia civil: el poder suave de China y la Unión Europea
}

\author{
From a strategy of charm to civil power: soft power \\ in China and the European Union
}

\section{Eduardo Tzili Apango*}

\section{Resumen}

Ante la erosión de la hard power (poder duro) estadounidense en el preludio del siglo xxi, emergen dos actores que mediante su soft power (poder suave) se vuelven referencia necesaria para países desarrollados y en desarrollo. Me refiero a la Unión Europea (UE) y China. Sin embargo, ¿serán lo mismo el poder suave europeo y el chino? ¿Cuál poder suave está adquiriendo más fortaleza en el ámbito global? Y con mayor énfasis: ¿será solo el poder suave un medio efectivo para adquirir el estatus al que tanto la UE como China aspiran? Trataré de responder estas interrogantes a lo largo del presente artículo de investigación.

Palabras clave: China, Unión Europea, poder suave, potencia global, influencia.

* Director Editorial Revista Académica Estudiantil Pensamiento Internacional. <e.tzili.a@ gmail.com>. Recibido el 5 de agosto de 2011; aceptado el 19 de octubre de 2011. 


\section{Abstract}

Given the erosion of the American hard power at the beginning of the $21^{\text {st }}$ century, it emerges two actors which trough its soft power became necessary reference to both developing and developed countries. I am referring to the European Union and China. However, will both European and Chinese soft power be the same? Which soft power is becoming stronger in the global arena? And more emphatically: will soft power be the only effective means to acquire the status pursued by China as well as by the European Union? This paper will attempt to provide an answer in the face of these uncertainties.

KEYwORDS: China, European Union, soft power, global power, influence. 
Eduardo Tzili Apango • De la estrategia del encanto a la potencia civil...

\section{INTRODUCCIÓN}

El presente artículo de investigación tiene como objetivo indagar entre las nuevas herramientas de estudio de las relaciones internacionales, a fin que contribuya a su enriquecimiento o al desafío de sus supuestos. Por ello, se eligió al poder suave como herramienta metodológica para realizar un estudio comparativo entre aquellos actores que son comúnmente identificados con el uso del mismo: la República Popular China y la Unión Europea.

El objetivo del escrito es observar si en efecto, el uso del poder suave augura un posicionamiento en el concierto de potencias para la configuración del ámbito global conforme a los intereses de dichos actores. Para dicho objetivo, también se tratará de comprobar si el poder suave es mesurable y, por otro lado, si se puede hablar de una capacidad unidimensional o de naturaleza múltiple.

Así, se dividirá el texto en cuatro apartados más las consideraciones finales. En el primero se expondrá de manera concisa en qué consiste el poder suave. El segundo describirá lo que los estudiosos identifican como característica del poder suave europeo; el tercero examinará lo mismo para el caso chino. En un cuarto apartado se compararán las capacidades suaves de ambos actores para que en las consideraciones finales se trate de responder a las preguntas planteadas en el resumen.

\section{EL PODER SUAVE.}

La caída del muro de Berlín trajo consigo una nueva complejidad en la manera en que se haría política a nivel internacional, dispersándose el concepto de power politics (política del poder), cuyo componente principal hasta finales de la década de 1980, el hard power (poder duro) dejó de ser referencia para la realización de las relaciones internacionales; el soft power (poder suave o blando) sería la antípoda del concepto antes mencionado, y que a su vez reflejaría la naturaleza cambiante del poder internacional (Nye, 1990).

Pero, ¿qué define al poder suave? Su máximo exponente, Joseph S. Nye Jr., lo define como un "poder de atracción» que yace principalmente en la cultura de un país, en sus valores políticos y en sus políticas exteriores (Nye, 2006). Por otro lado, Vuving (2009) diferencia entre el poder duro y el poder suave, pero remarcando las características de cada uno: coerción versus atracción. Concluye que el poder en sí mismo se coloca en un "continuo unidimensional»: de un lado la coerción y del otro la atracción. Interpretándolo, podría decirse que el poder duro es forzar a otros actores a hacer lo que un país quiere, mientras que el poder suave es convencerlos de lo mismo. Pero se sitúan en el mismo plano, ya que ambas maneras ejercen influencia. De una manera gráfica se podría colocar de la siguiente manera: 
Gráfico 1. Espectro de comportamientos

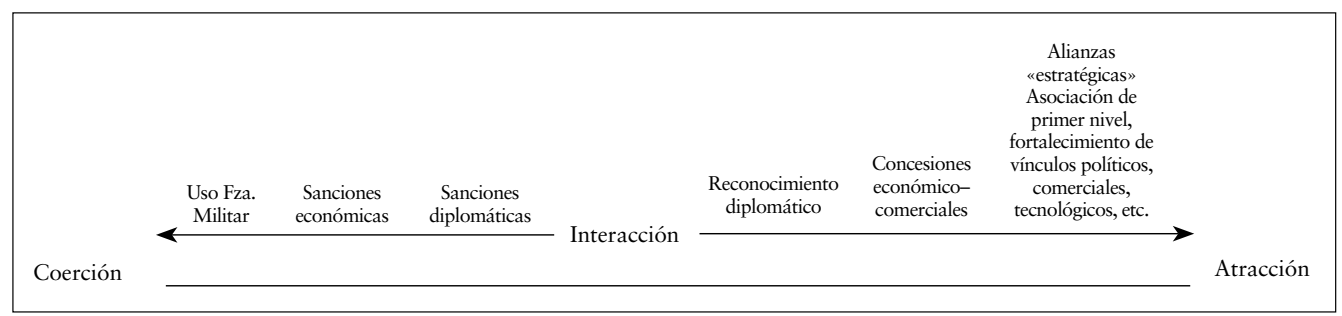

Fuente: Elaboración propia con base en Vuving (2009) y Nye (2011: 21).

El poder suave no nace en el contexto del fin de la Guerra Fría, siempre ha estado presente aunque en menor intensidad. Sin embargo, el hecho de que Nye lo considere como «el nuevo camino para triunfar en la política mundial» (Nye, 2004) no significa que el uso del poder duro haya quedado relegado a segundo término o simplemente haya desaparecido, sino que la naturaleza del poder ha cambiado: las relaciones internacionales adquirieron una nueva complejidad. La naturaleza de las interacciones entre las unidades del sistema internacional se ha modificado, y en este nuevo orden mundial el poder suave emerge como un instrumento adecuado para enfrentar los retos del siglo XXI: crimen transnacional, terrorismo, cambio climático, etc.

La invasión a Irak y Afganistán puso a prueba el poder duro y el unilateralismo estadounidense, aunque también evidenció que su uso aún está lejos de terminar. Pero también fue un intento de «forzar» el uso de la coerción en un orden mundial completamente diferente al de la Guerra Fría. Así, y desde hace tiempo, la Unión Europea (UE) y la República Popular China (RPCh) habían comprendido que el uso del "garrote» no les daría la capacidad necesaria para alcanzar sus objetivos a nivel global. Es por ello que desde el principio de la década de 1990 ambos países optaron por fortalecer sus capacidades «suaves»; no obstante, dicho poder difiere en su naturaleza, al punto de conseguir realizar el contraste entre poder suave europeo y poder suave chino.

Aunque el poder suave se relacione con la multilateralidad y la cooperación internacional, ello no significa que el conflicto haya desaparecido por completo. China va en ascenso y su énfasis en la soberanía nacional y en la multipolaridad (queriendo contrarrestar la «unipolaridad» estadounidense) (Scott, 2007), podrían hablar de una actitud hostil frente al otro actor en ascenso, la UE en su estatus de «potencia civil».

Por otro lado, pareciera que el poder suave europeo va rindiendo frutos en la manera de configurar a las relaciones internacionales. $\mathrm{Su}$ "auto-impuesto» deber por el fomento de la democra- 
Eduardo Tzili Apango • De la estrategia del encanto a la potencia civil...

cia y los derechos humanos es fuente de atracción, vía modelo político de desarrollo. Pero ¿qué divergencias se podrían encontrar en estos dos modelos de poder suave? ¿Serán diferentes en esencia? ¿Cuál de los dos podría considerarse «la vía más exitosa de triunfo» en la política mundial (si es que se pueden pensar así)? Se tratará de responder estas interrogantes en los subsecuentes apartados.

\section{EL PODER SUAVE EUROPEO: LA POTENCIA CIVIL}

A pesar que desde su fundación como la Comunidad Económica del Carbón y del Acero $^{1}$ y más tarde la Comunidad Económica Europea, ${ }^{2}$ el continente ha desarrollado fuertes vínculos económico-comerciales con terceros países, ejerciendo un tipo de influencia con base en el poder suave que le daba la atracción económica, como la fijación de una tarifa externa y una política comercial común a terceros países (Whitman, 1997); ello sería socavado por el contexto de la Guerra Fría, donde ineludiblemente el uso del poder duro mantendría a raya todo desempeño importante en el plano de las low politics (políticas bajas). ${ }^{3}$

La disolución de la Unión Soviética como sujeto de derecho internacional

\footnotetext{
Tratado Constitutivo, 1951

Tratado de Roma, 1957

Se podría aseverar que el poder suave es el medio de ejercer la política baja, con base en Del Arenal (1993: 411)
}

(y todo lo que ello contrajo) representó una nueva oportunidad para la naciente Unión Europea ${ }^{4}$ de posicionarse como un actor relevante que daría forma al nuevo orden mundial; ello con base en principios europeos como la democracia y los derechos humanos, a manera de «enmarcar éticamente la mundialización» (Barbé, 2005).

Así, la Unión Europea se ha dotado de una identidad propia en el marco internacional, caracterizándose por el uso extensivo de métodos pacíficos y con un fuerte contenido económico, social y político y con incidencia en las estructuras sociales económicas y políticas de sus socios, convirtiéndose en lo que algunos analistas llaman "potencia civil» con «poder de transformación».

¿Con base en qué criterios podemos identificar a la UE como "potencia civil»? Esther Barbé (2000: 111) sostiene que dicho estatus fue adquirido por la UE a causa de la influencia a nivel internacional, mismo que venía desde la formulación de la Cooperación Política Europa (CPE, antecedente de la Política Exterior y de Seguridad Común, o PESC) a través de su poder económico, su prestigio como modelo exitoso ( «zona de paz») y su capacidad de ser una voz alternativa a los Estados Unidos en la esfera occidental.

Relacionado con lo anterior, incluso se ha llegado a manifestar la existencia de una «demanda de Europa», ello vinculado a su experiencia en materia de integración regional, de su disponi-

4 Tratado de la UE, 1992 
bilidad de afrontar crisis humanitarias, y de los valores de su participación y tolerancia social comunes en los países de la unión (Solana, 2003). Empero, el desacuerdo sobre una posición común frente al régimen de Saddam Hussein después de la Guerra del Golfo (1991), la falta de acción comunitaria decisiva contra el genocidio en Ruanda (1998) y el no apoyo a la iniciativa italiana de responder ante el colapso del orden civil en Albania (2003), han sido grandes ejemplos de que la «potencia civil» no tiene el poder suficiente para influir en la manera en que ella misma desea: no hay capacidades para fomentar el respeto a los derechos humanos y la democracia.

Lo anterior es reflejo de que la UEaún no ha logrado alcanzar el balance entre poder duro y poder suave (lo que algunos estudiosos llaman smart power o poder inteligente) (Nye, 2006) (Vuving, 2009) (Nossel, 2004) (Ferrero-Waldner, 2007), lo que a su vez resta importancia a la UE como actor capaz de dar forma a las relaciones internacionales y que ello sirva a intereses estratégicos. En contraste con lo mencionado anteriormente, otros analistas (Smith, 2000) aseguran que el estatus de «potencia civil» ha sido adquirido por la UE a causa de los medios estrictamente civiles (como ayuda financiera o diálogo político) y que para alcanzar el cumplimiento de metas a largo plazo (sobre todo las relacionadas con los derechos humanos, la democracia y el cambio climático), Europa debe adquirir consistencia en su PESC, enfocado en desarrollar sus habilidades de «intervención». Ello por supuesto haría que abandonase su nombramiento de "potencia civil», lo que ya le ha valido cierto prestigio.

A manera general, se puede observar que la esencia del poder suave europeo descansa en la utilización de medios civiles que conceden un nivel importante de influencia a escala global. El hecho de que se le reconozca como "potencia civil» no significa que se le identifique como una potencia global capaz de hacer frente al poder duro y al unilateralismo estadounidense, y a los retos mundiales del siglo xxi, que aunque demandan uso de poder suave, los ejemplos ya citados (Albania el más significativo, por ser parte de la zona de influencia europea) manifiestan que sería deseable que la UE desarrollara un poder inteligente.

\section{El PODER SUAVE CHINO: THE CHARM OFFENSIVE"}

En el caso de la RPch, el inicio de la formulación del poder suave inició, de manera implícita, con la reforma económica llevada a cabo por Deng Xiaoping" a finales de la década de 1970, llegado a consolidar una política exterior con base en los cinco principios de coexistencia pacífica (1982), ${ }^{5}$ resul-

Término utilizado más en inglés, y que literalmente se traduciría como «encanto ofensivo» u «ofensiva encantadora». Véase: Kurlantzick (2007)

* Para el caso del uso del idioma chino en el presente trabajo, se utilizará el sistema pin-yin, método oficial de transliteración de caracteres chinos a lenguas romances, 
Eduardo Tzili Apango • De la estrategia del encanto a la potencia civil...

tando a su vez en la formulación de los conceptos de «ascenso» y «desarrollo» pacíficos» (Bijian, 2005) para explicar el progreso de China en la escena política y económica mundial. Así, durante el periodo de Deng, el liderazgo del Partido Comunista de China (PCCh) desarrollaría una "gran estrategia diplomática» para configurar, y no simplemente responder, al sistema internacional. Es decir, priorizó el uso del poder suave, a través de un adquirido compromiso con la multipolaridad en temas globales y la creación de una red de vínculos bilaterales para la resolución de problemas comunes (Roch, 2008).

¿Cómo identificar los componentes del poder suave chino? Kurlantzick (2007: 46) lo resume de la siguiente manera: «cuando el gobierno chino habla acerca de su nuevo poder suave en el mundo, se refiere a todo aquél poder afuera de la esfera militar, incluyendo la diplomacia, la herramienta económica, de inversiones y de ayuda». En este sentido, uno de los aspectos más atractivos del poder suave chino es el llamado "Consenso de Beijing», que refuta las nociones occidentales de liberalización política o reformas económicas como indispensables a largo plazo (Thompson, 2005).

adoptado oficialmente en China a partir de 1982. Se excluyen los acentos tonales.

5 A) Respeto mutuo a la soberanía e integridad territorial, B) No agresión, C) No intervención en los asuntos internos de otro país, D) Igualdad y beneficio recíproco y E) Coexistencia pacífica. Véase: Connelly (1991)
Es decir que, a diferencia del europeo, el poder suave chino es más económico. Al carecer de una legitimidad que provenga de elecciones, el gobierno chino ha encaminado sus esfuerzos al desarrollo económico interior (Kurlantzick, 2007: 42). Para ello busca asegurar recursos naturales y económicos así como mercados para sus productos, lo que ha llevado a China a que sea puesta en la mira de otros países que ven con recelo su incursión en el comercio internacional. La República Popular ha enfatizado que en su inevitable ascenso no buscará la hegemonía ni el control de recursos o mercados vía poder duro, haciendo eco de la doctrina del desarrollo pacífico, anteriormente mencionada.

Sin embargo: "muchos países confían en que China seguirá un 'ascenso pacífico' pero ninguno apostaría su futuro a tal cosa", mencionaba el ex subsecretario de Estado estadounidense, Robert B. Zoellick, lo que expresa una desconfianza hacia el gigante asiático, dado que su innegable desarrollo económico también se aplica al desarrollo de sus capacidades duras de poder. Aunque, afirma el vocero de la sesión anual de la legislatura nacional de China, Li Zhaoxing (2011):

Es verdad que el presupuesto de defensa de China se han incrementado un poco, pero la proporción del gasto de defensa en el pib del país sigue siendo muy baja, mucho más baja que la de muchos otros países [...].La limitada fortaleza militar de China está destinada exclusivamente a salvaguardar su soberanía nacional e integridad territorial y no represen- 
tará ninguna amenaza para ningún país. China está comprometida con el desarrollo pacífico y con una política de defensa nacional que tenga una naturaleza defensiva.

Es por ello que el uso del poder suave por parte de China ha sido catalogado como una charm offensive, o una "estrategia del encanto» (Rosas, 2007), lo que ocasiona escepticismo en la política internacional. A diferencia de la UE, cuyas capacidades duras de poder aún no están del todo desarrolladas, China podría presentar, en efecto, una amenaza a diversos actores de las relaciones internacionales, sobre todo Estados Unidos (por la cuestión de Taiwán). En este discernimiento, no ha existido país que haya realizado esfuerzos de manera tan sistemática para proyectar una imagen constructiva en el área internacional e identificarse con el poder suave (Toro Hardy, 2010).

Habiendo expuesto las características generales del poder suave chino y europeo, utilizando el método comparativo, se analizan las posibles divergencias entre los actores que lo ejercen, así como probables convergencias que pudieran evitar un hipotético conflicto.

\section{Correlaciones ENTRE}

\section{EL PODER SUAVE EUROPEO}

\section{Y CHINO: UN ESTUDIO}

\section{COMPARATIVO}

En este apartado se identificarán los elementos comunes que en su conjunto conformarían el poder suave para, de alguna manera, medirlos y así poder hacer un análisis comparativo al respecto.

Según Nye (2006), como ya se mencionó en líneas anteriores, los mecanismos que dan forma al poder suave son la cultura de un país, sus valores políticos y sus políticas exteriores. ¿Cómo medir eso? Siguiendo esa misma línea, Vuving (2009) delimita los componentes del mencionado poder en lo que él llama: belleza, brillantez (o brillo) y benignidad (o bondad).

Empero, lo anterior lo localiza en el campo de la subjetividad, ya que para el autor antes mencionado estas características de poder suave se refieren más a las consecuencias que a las causas materiales, ya que provocan comportamientos no egoístas, benevolencia, gratitud, asombro, respeto, admiración y atracción (2009: 12-16).

A pesar de lo antepuesto, el mismo autor también da una serie de factores que bien podrían servir a nuestro análisis. Les llama las «herramientas del poder suave» y en resumidas cuentas, se pueden visualizar las siguientes:

- Herramientas que producen poder suave indirectamente: eventos culturales, programas de intercambio, emisiones (noticias, programas televisivos, etc.), asistencia humanitaria y enseñanza de la lengua extranjera;

- Herramientas que producen poder suave directamente: "mitos» (poderosa herramienta que puede configurar las opiniones y deseos de terceros), fomento de la multilateralidad, asistencia económica, 
Eduardo Tzili Apango • De la estrategia del encanto a la potencia civil...

apoyo diplomático y conducta de la política exterior con base en principios normativos (lo que incluye llevarla a nivel de organismos internacionales).

Estos elementos bien podrían ser medibles para la causa de la investigación. Empero, aun habiendo especificado los instrumentos que producen el poder suave, es un tanto difícil constatar la obtención de poder sin con ello recaer en el simplismo de la cantidad sobre la calidad. Es por ello que del primer campo solo se tomarán los programas de intercambio (que incluirían sobre todo becas para estudios superiores), la asistencia humanitaria y la enseñanza de la lengua extranjera, al ser el impacto de los otros factores, muy difuso de medir.

Del primer rubro (programas de intercambio con base en becas para educación superior), las iniciativas más importantes son: la Comisión de Becas de la RPCh (CsC por su sigla en inglés) y Erasmus Mundus de la UE, aunque no son las únicas. Durante el periodo escolar 2008-2009, la csc otorgó un total de 6,831 becas nuevas (en razón de un incremento de $15.37 \%$ del periodo anterior) (China Scholarship Council Web Page, 2008). Por otro lado, Erasmus Mundus otorgó un total de 2,031 nuevas becas (en razón de un incremento del $8.53 \%$ respecto del período anterior) (Europe: Executive Agency. Education, Audiovisual \& Culture, 2009). Tales becas se otorgan en su mayoría a la región de África $(31.47 \%$ del total en el caso de China, $\pm 33.15 \%$ en el caso de la UE). ${ }^{6}$

De lo inicial se podría deducir que en efecto se busca más presencia de China y la uE en el mundo mediante la educación. Para ambos actores internacionales, la inversión educativa es de prioridad, desde que ambos adquirieron metas a largo plazo que seguir (la UE para cumplimiento de su «Marco Estratégico de Educación y Entrenamiento", y China para el cumplimiento de una de sus cuatro modernizaciones). El hecho de que la mayoría de dichos incentivos se enfoquen en África habla del nuevo juego de geopolítica global, donde dicho continente ha adquirido relevancia importante por sus recursos energéticos y donde las dos potencias en ascenso buscan asegurar zonas de influencia.

En lo que se refiere a la asistencia humanitaria, entendiéndose esta como "la ayuda en concordancia con los principios humanitarios: humanidad, neutralidad e imparcialidad, y que va encaminada a aliviar el sufrimiento causado por desastres naturales o artificiales, dando prioridad a los grupos más vulnerables y sin adquirir tintes políticos o bélicos [...]» (AG/46/182, 1991), tanto la UE como China van obteniendo prestigio tanto por sus contribuciones, como por su participación directa en la resolución de diversos

6 En el caso de la ue, los datos duros pueden ser imprecisos dada la cantidad de países que conforman a la Unión. Por eso se coloca « \pm ", con base en Europe: Executive Agency. Education, Audiovisual \& Culture (2009). Elaboración propia del último porcentaje 
conflictos que pudieran ocasionar un desastre humanitario a gran escala. En esta línea, la UE presume de ser la primera donante a nivel mundial y aunque contiene lagunas la legislación de la Unión, le proporciona al continente europeo un prestigio que ningún otro actor en el mundo posee (Cortázar, s/a).

«La integración de China en los mecanismos multilaterales para la resolución de problemáticas globales es uno de los retos más grandes que la comunidad internacional enfrente para el siglo XXI» (Binder y Conrad, 2009). Así, mientras Beijing recibió 18.5 millones de dólares de Ayuda Oficial para el Desarrollo (AOD), solo donó 0,5. Por otro lado, la UE (a través de la Comisión Europea) donó 1.5 mil millones de dólares, sin recibir ayuda de ningún tipo, siendo uno de los pocos entes internacionales que no la absorbe (Global Humanitarian Assistance, 2011).

De lo anterior se puede comprobar cómo la UE se ganó su título de potencia civil «a pulso", aunque también es conocido que el hecho de que China no sea un país desarrollado, sino un país en desarrollo, de alguna manera, lo exime de ser un donador grande. Así, su «esfuerzo» por donar dinero a operaciones humanitarias podría ser visto como una "generosidad significativa", a diferencia de la UE que tiene la capacidad para hacerlo.

La asistencia humanitaria se complementa con el envío de ayuda «en especie», que usualmente es la participación de los países en misiones de paz, a las que envían tropas, especialistas en desastres civiles o naturales, observadores militares o civiles, etc., para contribuir al arreglo del conflicto en cuestión. Luego entonces, para el caso de China se observa un importante pero discreto despliegue de tropas para las misiones de mantenimiento de paz de las Naciones Unidas: 2,167 efectivos divididos en 12 operaciones, en contraste con el despliegue de 8,129 tropas divididas en 4 operaciones (en ambos casos, los datos corresponden a 2009) (Barcelona Centre for International Affairs сіDов, 2009).

Habría que recalcar que mientras casi toda la participación de China se hace bajo la bandera de las Naciones Unidas, el caso de la Ue es diferente, ya que varía entre las Naciones Unidas, y la Organización del Tratado del Atlántico Norte (OTAN); sumando todas las aportaciones de a los tres organismos, tenemos que entonces la UE ha enviado un total de 51,359 tropas. (Véase el Cuadro 1) 
Eduardo Tzili Apango • De la estrategia del encanto a la potencia civil...

Cuadro 1. Contribución de tropas a las Operaciones

para el Mantenimiento de la Paz (2009).

\begin{tabular}{|c|c|c|c|c|c|c|c|c|}
\hline \multicolumn{3}{|c|}{ China: contribución de tropas } & \multicolumn{6}{|c|}{ Unión Europea: contribución de tropas } \\
\hline Misión & 2009 & $\begin{array}{l}\text { Total } \\
\text { tropas }\end{array}$ & Misión & 2009 & $\begin{array}{l}\text { Total } \\
\text { tropas }\end{array}$ & Misión & 2009 & $\begin{array}{l}\text { Total } \\
\text { tropas }\end{array}$ \\
\hline $\begin{array}{l}\text { Misión de las Naciones } \\
\text { Unidas para el Referén- } \\
\text { dum en el Sahara Occi- } \\
\text { dental (MINURSO)* }\end{array}$ & 13 & 225 & $\begin{array}{c}\text { Misión de las Na- } \\
\text { ciones Unidas para } \\
\text { el Referéndum en el } \\
\text { Sahara Occidental } \\
\text { (MINURSO) }\end{array}$ & 35 & & $\begin{array}{l}\text { Fuerza de la } \\
\text { Unión Euro- } \\
\text { pea en Bos- } \\
\text { nia-Herzego- } \\
\text { vina (EUFOR- } \\
\text { ALTHEA) }\end{array}$ & 1,641 & \\
\hline $\begin{array}{c}\text { Misión de las Naciones } \\
\text { Unidas para la Estabi- } \\
\text { lización en Haití (MIN- } \\
\text { USTAH) }\end{array}$ & 145 & 8,879 & $\begin{array}{l}\text { Misión de las Na- } \\
\text { ciones Unidas para } \\
\text { la Estabilización en } \\
\text { Haití (MINUSTAH) }\end{array}$ & 118 & & $\begin{array}{l}\text { Fuerza de } \\
\text { la Unión } \\
\text { Europea en } \\
\text { República } \\
\text { Democrática } \\
\text { del Congo } \\
\text { RDC (EUFOR) }\end{array}$ & 407 & \\
\hline $\begin{array}{l}\text { Misión de las Naciones } \\
\text { Unidas para la Estabi- } \\
\text { lización en República } \\
\text { Democrática del Congo } \\
\text { (MONUC) }\end{array}$ & 234 & 18,434 & $\begin{array}{l}\text { Misión de las Na- } \\
\text { ciones Unidas para } \\
\text { la Estabilización en } \\
\text { la República Demo- } \\
\text { crática del Congo } \\
\text { (MONUC) }\end{array}$ & 105 & & $\begin{array}{l}\text { Misión Po- } \\
\text { liciáca de la } \\
\text { Unión Euro- } \\
\text { pea en Bos- } \\
\text { nia-Herzego- } \\
\text { vina (EUPM) }\end{array}$ & 116 & \\
\hline $\begin{array}{l}\text { Misión de las Naciones } \\
\text { Unidas-Unión Africana } \\
\text { en Darfur (UNAMID) }\end{array}$ & 323 & 10,667 & $\begin{array}{l}\text { Misión de las } \\
\text { Naciones Unidas - } \\
\text { Unión Africana en } \\
\text { Darfur (UNMID) * }\end{array}$ & 18 & & $\begin{array}{c}\text { Total Unión } \\
\text { Europea (EU) }\end{array}$ & & $\underset{* * *}{2,474}$ \\
\hline $\begin{array}{c}\text { Fuerza de las Naciones } \\
\text { Unidas en Líbano } \\
\text { (UNFIL) }\end{array}$ & 343 & 12,543 & $\begin{array}{l}\text { Misión de las } \\
\text { Naciones Unidas - } \\
\text { Unión Africana en } \\
\text { Darfur (UNFIL) }\end{array}$ & 5,750 & & $\begin{array}{l}\text { Fuerza de } \\
\text { Asistencia } \\
\text { para la Segu- } \\
\text { ridad Interna- } \\
\text { cional (ISAF) }\end{array}$ & 30,789 & \\
\hline $\begin{array}{l}\text { Misión de Naciones } \\
\text { Unidas en Etiopía y } \\
\text { Eritrea (UNMEE) }\end{array}$ & 2 & 308 & $\begin{array}{c}\text { Misión de las } \\
\text { Naciones Unidas } \\
\text { en República Cen- } \\
\text { troafricana y Chad } \\
\text { (MINURCAT) } \\
\end{array}$ & 572 & & $\begin{array}{l}\text { Fuerza de la } \\
\text { OTAN para } \\
\text { Kosovo } \\
\text { (KFOR) }\end{array}$ & 9,967 & \\
\hline $\begin{array}{l}\text { Misión Interina de las } \\
\text { Naciones Unidas sobre } \\
\text { la Administración de } \\
\text { Kosovo (UNMIK) }\end{array}$ & 18 & 1,939 & $\begin{array}{l}\text { Misión Interina de } \\
\text { las Naciones Unidas } \\
\text { sobre la Adminis- } \\
\text { tración de Kosovo } \\
\text { (UNMIK) }\end{array}$ & 8 & & $\begin{array}{l}\text { Total Orga- } \\
\text { nización del } \\
\text { Tratado para } \\
\text { el Atlántico } \\
\text { Norte (OTAN) }\end{array}$ & & $\begin{array}{l}40,756 \\
+\end{array}$ \\
\hline
\end{tabular}


Estudios Internacionales I70 (201 I) • Universidad de Chile

\begin{tabular}{|c|c|c|c|c|c|c|c|}
\hline $\begin{array}{c}\text { Misión de las Naciones } \\
\text { Unidas en Liberia } \\
\text { (UNMIL) }\end{array}$ & 578 & 12,708 & $\begin{array}{l}\text { Misión de las Na- } \\
\text { ciones Unidas en } \\
\text { Liberia (UNMIL) }\end{array}$ & 38 & & \multirow[t]{11}{*}{ Total } & \multirow[t]{11}{*}{51,359} \\
\hline $\begin{array}{c}\text { Misión de las Naciones } \\
\text { Unidas en Sudán } \\
\text { (UNMIS) }\end{array}$ & 476 & 9,933 & $\begin{array}{l}\text { Misión de las Na- } \\
\text { ciones Unidas en } \\
\text { Sudán (UNMIS) }\end{array}$ & 105 & & & \\
\hline $\begin{array}{l}\text { Misión Integrada de } \\
\text { las Naciones Unidas en } \\
\text { Timor-Leste (UNMIT) }\end{array}$ & 23 & 1,575 & $\begin{array}{c}\text { Fuerza Observadora } \\
\text { del Cese al Fuego de } \\
\text { las Naciones Unidas } \\
\text { (UNDOF) }\end{array}$ & 386 & & & \\
\hline $\begin{array}{l}\text { Operación de las Na- } \\
\text { ciones Unidas en Côte } \\
\text { d'Ivoire (UNOCI) }\end{array}$ & 8 & 9,153 & $\begin{array}{c}\text { Operación de las } \\
\text { Naciones Unidas } \\
\text { en Côte d'Ivoire } \\
\text { (UNOCI) }\end{array}$ & 35 & & & \\
\hline $\begin{array}{c}\text { Organización para la } \\
\text { Supervisión de Treguas } \\
\text { de las Naciones Unidas } \\
\text { (UNTSO) }\end{array}$ & 4 & 154 & $\begin{array}{l}\text { Organización para } \\
\text { la Supervisión de } \\
\text { Treguas de las } \\
\text { Naciones Unidas } \\
\text { (UNTSO) }\end{array}$ & 81 & & & \\
\hline $\begin{array}{c}\text { Total Naciones Unidas } \\
\text { (UN) }\end{array}$ & 2,167 & 86,518 & $\begin{array}{c}\text { Misión Integrada de } \\
\text { las Naciones Uni- } \\
\text { das en Timor-Leste } \\
\text { (UNMIT) } \\
\end{array}$ & 264 & & & \\
\hline Total & 2,167 & 86,518 & $\begin{array}{l}\text { Fuerza para el Man- } \\
\text { tenimiento de la } \\
\text { Paz de las Naciones } \\
\text { Unidas en Chipre } \\
\text { (UNFICYP) }\end{array}$ & 585 & & & \\
\hline \multirow{5}{*}{\multicolumn{3}{|c|}{$\begin{array}{l}\text { *Las siglas sin en inglés } \\
* \text { En cooperación con la Unión Africana }\end{array}$}} & $\begin{array}{l}\text { Misión de las Na- } \\
\text { ciones Unidas en } \\
\text { Nepal (UNMIN) }\end{array}$ & 11 & & & \\
\hline & & & $\begin{array}{c}\text { Grupo Militar } \\
\text { Observador de las } \\
\text { Naciones Unidas } \\
\text { en India y Pakistán } \\
\text { (UNMOGYP) } \\
\end{array}$ & 18 & & & \\
\hline & & & $\begin{array}{l}\text { Total Naciones } \\
\text { Unidas (UN) }\end{array}$ & & 8,129 & & \\
\hline & & & $\begin{array}{c}\text { Misión de Moni- } \\
\text { toreo de la Union } \\
\text { Europea en Georgia } \\
\text { (EUMM) } \\
\end{array}$ & 310 & & & \\
\hline & & & \multicolumn{5}{|c|}{$\begin{array}{c}* \text { En cooperación con la Unión Africana, } * *, * * \text { y }+ \text { son el total de tropas } \\
\text { calculadas por país, no por misión. }\end{array}$} \\
\hline
\end{tabular}

Fuente: Global Humanitarian Assistance y

Barcelona Centre for International Affairs CIDOB (2009) 
Eduardo Tzili Apango • De la estrategia del encanto a la potencia civil...

El número evidentemente mayor de tropas europeas en las OMP responde a la lógica del ejercicio de la UE como potencia civil, además del respeto irrestricto de China ante lo que considera una «violación de la soberanía nacional», el ejercicio del intervencionismo. Habría que estudiar si las acciones de la OTAN corresponden, en su amplitud, a OMP, ya que su carácter es más bélico que de asistencia humanitaria y ello correspondería entonces a que la UE solo haya participado con 10,603 efectivos destinados exclusivamente a cuestiones humanitarias, cantidad que aún supera por mucho las contribuciones chinas.

Una vez vista una comparación de las participaciones de ambos actores en asistencia humanitaria, se enfocará la enseñanza de la lengua extranjera, identificado, como otro instrumento de propagación de poder suave. El idioma se identifica como parte de la cultura, elemento fundamental de dicho poder (Rosas, 2007). En este sentido, María Cristina Rosas muestra que la expansión del putonghua se ha efectuado a través de los llamados Institutos Confucio, reproduciendo la fórmula francesa de la Alianza Francesa, o la fórmula inglesa del Consejo Británico.

Es difícil realizar una comparación entre la influencia que producen los idiomas chinos y los idiomas que componen la UE. De inicio, habría que recalcar que el putonghua, o chino mandarín simplificado, es un logro del gobierno de China que entre 1956 y 1964 promovió la reforma para que en todo el país se entendiera la escritura china (Lien-Tan, 2005). Dicho sea en otras palabras, al interior, pareciera que China, pese a sus numerosas nacionalidades (por ende, numerosas lenguas), ha establecido una "escritura franca» más que una lengua franca en el afán de unificar la comunicación entre sus 1 , 300 millones de habitantes (promedio), algo que no ha hecho la ue (aunque se podría decir que el inglés, y en menor medida el francés, actúan como lenguas francas).

No hay tal cosa como una escuela o institución que se dedique a la enseñanza de la «lengua europea», cosa que tampoco existe. En este sentido, se puede observar que dado el ascenso de China, cada vez más personas desean adquirir el chino mandarín como segunda lengua (sobre todo a raíz de su aceptación en la Organización Mundial de Comercio), ${ }^{7}$ y aunque la popularidad del francés, del alemán o del inglés se mantiene, los franco-parlantes, germano-parlantes o anglo-parlantes no se incrementan tanto como los sinoparlantes. ${ }^{8}$

Como ya se dijo, el inglés actuaría como lengua franca dentro del continente europeo. Pero a diferencia de China, la UE se preocupa más por el desarrollo de un multilingüismo al

Véase: Diario del Pueblo (2002), Foreign Language (2007) y BBC Mundo (2011) por mencionar algunas notas periodísticas que reflejan el nivel de percepción del impacto del chino mandarín a nivel global.

8 Véase para mayor referencia: Embajada Alemana en México (2010) y European Comission Multilingualism (2010) como ejemplos 
interior, mientras que la RPCh se preocupa por su expansión lingüística en el exterior, lo que refleja, entre otras cosas, el deseo de la Unión de seguir consolidándose y fortaleciéndose a nivel interno, pero que también habla de una incapacidad de utilizar esta herramienta de poder suave en toda su extensión y para cumplimiento de objetivos de interés comunitario.

A partir de éstas líneas, se concentrará en las herramientas que producen poder suave de una manera directa. Esto, como se vio anteriormente, incluye la formulación de «mitos», fomento de la multilateralidad, asistencia económica, apoyo diplomático y conducta de la política exterior con base en principios normativos.

En lo que a «mitos» se refiere, estos ueden ser utilizados para comunicar benignidad, brillantez y belleza (las consecuencias subjetivas a las que me refiero al principio del presente apartado). Vuving coloca el ejemplo que ante el uso de elementos de poder duro, como victorias militares, la «belleza» que algunos aprecian del mismo puede ser explotado para crear mitos de invencibilidad e inevitabilidad (2009: 13). Es decir, para atemperar imágenes hacia el exterior, erigirse prestigio o reputación, los actores en cuestión pueden hacer uso de la difusión y/o propaganda para crearse «mitos» sobre sus capacidades, que resulten de manera favorable a los intereses que persiguen. Esto, como «regla», debe ser de manera que no produzca elementos negativos o agresivos.
Observando a lo anterior, tanto la doctrina de "potencia civil» de la UE, como el principio del «desarrollo pacífico» de China, consiguen discurrirse en los mejores ejemplos de «mitos» que contrarrestan influencias negativas acerca de su imagen en el ámbito internacional. En el caso de Europa, es criticada la posición que asume a Unión al momento de querer fortalecer la PESC (lo que llevaría, como en su momento se enfatizó, al abandono de su estatus civil) (Smith, 2000: 12-13) para cumplimiento de las denominadas «tareas de Peterberg», que induce necesariamente al desarrollo de la capacidad de intervención (en algunos casos, como se advirtió ejemplificando anteriormente la situación de Bosnia-Herzegovina). Siguiendo ello, la posesión de efectivos militares habla de un estatus muy contrario al de una potencia civil, como argumenta Karen Smith (2005: 9): «[...] definimos a los 'peacekeepers' como instrumento militar, y un actor que posea dicho instrumento no es una potencia civil pura».

Pero he aquí otro elemento no considerado con anterioridad y que también ha servido para construir el «mito" de la potencia civil: la cooperación internacional para el desarrollo (CID): «La UE, potencia económica y civil mundial, es reconocida a escala global como el actor más relevante y proactivo en torno a la CID» (Prado Lallande, 2010: 82). En esta línea, desde mediados de la década de 1990, la comunidad europea ha emprendido una ambiciosa reforma de su CID, incorporando el 
Eduardo Tzili Apango • De la estrategia del encanto a la potencia civil...

nuevo "Consenso» internacional sobre el desarrollo, los Objetivos del Desarrollo del Milenio (ODM) y el principio de «asociación» (Sanahuja, 2004); empero, ha existido la tendencia a «desviar la ayuda», como bien lo hace notar José Antonio Sanahuja:

El Comité de Ayuda al Desarrollo ha destacado la falta de congruencia de la distribución de la ayuda humanitaria por áreas geográficas y niveles de renta, y el objetivo de lucha contra la pobreza.

En 1999 los 10 principales receptores de AOD se encontraban en Asia y África, pero en 2000 todos eran balcánicos y mediterráneos [...] Casi todo el aumento de la ayuda se destinó a los países en los que están en juego otros intereses.

En lo que concierne a China, la tesis del «ascenso pacífico «(más tarde convertida en desarrollo pacífico) fue expuesta por Zheng Bijian (2005) para responder a las teorías que hablaban de la «amenaza china». En ella se expone que "China no busca la hegemonía o el predominio en los asuntos globales»; o en palabras del actual premier chino: «el ascenso de China no se produce a costa de ningún país».

La «amenaza china» es percibida con más intensidad en los Estados Unidos: «[...] algunas personas han elegido interpretar la emergencia de China como una superpotencia económica y militar como una amenaza a la seguridad de los Estados Unidos y del Asia-Pacífico en general» (Broomfield, 2003: 265), aunque también pareciera que su desarrollo pacífico, en algún momento, entraría en conflicto con el desarrollo europeo:

Tanto la política exterior como interior de China ha seguido un camino en donde le presta poca o nula atención a los valores europeos, y hoy por hoy Beijing regularmente los contraviene o socava sus efectos [...] China ha aprendido a explotar la división entre los Estados miembros de la Unión (Fox y Godement, 2009).

Los párrafos anteriores demuestran cómo ambos actores se han visto en la necesidad de articular "mitos» que rescaten la mala imagen que se ha construido alrededor de su esencia, y determinadas acciones incrementan o reducen la creencia a dicho mito: la indecisión inicial con la que la ue tardó en actuar en el conflicto interno libio, o la decisión de China de enviar tropas de asistencia humanitaria a Haití (país que no lo reconoce diplomáticamente), si bien responden a intereses particulares, también son ejemplos de lo anteriormente dicho.

En materia del fomento a la multilateralidad, surge un contraste entre la UE y China aunque pareciera que ambos buscan un contra-balance a la unilateralidad estadounidense. Por una parte, la Unión Europea tiene a bien haber construido toda una orientación hacia la multilateralidad (siguiendo los principios de la Escuela inglesa de las relaciones internacionales) (Scott, 2007). Frente a ello, China pone énfasis en la construcción de un mundo multipolar, destacando su ascenso como gran 
potencia en el sistema internacional, en lugar de aceptar normas externas en una sociedad internacional (erigiendo los principios de la teoría realista de las relaciones internacionales) (Scott, 2007).

¿Qué implicaciones tiene la búsqueda de una multilateralidad o una multipolaridad?:

Mientras que las estructuras de tipo «polar» están definidos por los principios de exclusión y de negación, el multilateralismo se caracteriza por el principio de complementariedad. A nivel mundial aún no es una realidad plena [...]. En escalas menores pero con seguridad más orgánicas, la mejor configuración de experiencia multilateral es, sin duda alguna, la construcción de la Unión Europea (Maldonado, 2005: 200).

Así, y con razón, China causa escepticismo a nivel internacional dado su deseo de fomento de la multipolaridad: el reconocimiento de varios centros de poder que convergen y divergen en un sistema internacional determinado, bajo una estricta jerarquía. Europa, por su lado y en palabras del otrora Alto Representante del Consejo de la UE para la Política Exterior y de Seguridad Común, Javier Solana, está «comprometida con el multilateralismo».

El siguiente punto que Vuving destaca es la asistencia económica. Ya se vio una parte en lo que se refiere a la AOD, pero dicha asistencia puede adquirir otros matices; inversión el más representativo. Así, mucha de la asistencia económica de China no constituye AOD, medida bajo parámetros de la Organización para la Cooperación y el Desarrollo Económicos (OCDE) (Lum, 2009).

Se calcula que para finales del 2009 , China proveyó un total de $38.83 \mathrm{mil}$ millones de dólares en rubro de asistencia económica al extranjero (Diario del Pueblo, 2011), mientras que la UE otorgó \pm 71.45 mil millones de dólares (Partido Nacional Británico, 2011). Evidentemente, en su condición de potencia económica la UE puede otorgar más ayuda económica en forma de inversiones o préstamos a bajas tasas de interés y China está muy por debajo de la media europea, sin posibilidades de alcanzarla en el futuro inmediato.

Hablando de la asistencia económica, la «batalla» más fuerte entre los dos actores en cuestión es, sin duda, África (donde también se manifiesta la mayor cantidad de asistencia económica china): «mientras la UE permanece como la primera presencia externa a lo largo de todo el continente, su influencia decrece relativamente a China. El comercio chino con África se expande a razón de $33 \%$ anual frente al 6\% de la UE» (Fox y Godement, 2009: 9). La asistencia económica se enmarca en lo que ya se había aludido como el «Consenso de Beijing» o el «desarrollo económico con características chinas», lo que incluye respetar la soberanía de otros países (no interviniendo en asuntos internos) y, lo que es más significativo, ayuda técnica y financiera sin condiciones (Thompson, 2005).

A diferencia de China, en la UE la condicionalidad para otorgar AOD y/o 
Eduardo Tzili Apango • De la estrategia del encanto a la potencia civil...

asistencia económico-financiera se ha venido incrementando desde la firma del Tratado de Maastricht. Si bien se le considera como la última herramienta que revele un ejercicio de poder de parte de la Unión, en los actuales tratados y comunicados de sus instituciones revelan que otorgan cada vez más importancia a la promoción de los valores europeos, llegando a condicionar la ayuda en caso de que no se cumplan los mismos. ${ }^{9}$

La exposición de la situación de la asistencia económica demuestra una curiosa paradoja: aunque la colaboración europea sea casi el doble que la china, países en vías de desarrollo (sobre todo los africanos), donde aún se tiene que construir un respeto a los derechos humanos y la democracia, y donde no se cumplen los deberes que dichos países tienen ante la comunidad internacional (lo que constituiría, en caso de que lo hiciesen, en la formación de una sociedad internacional a la usanza europea), prefieren la asistencia china debido a la naturaleza sin condiciones del "Consenso de Beijing». Esto no representa un rechazo total de parte de China a las reformas económicas o políticas que fomenten el «buen gobierno», pero es más cautelosa a la hora de apoyar iniciativas occidentales que puedan socavar su nivel interno(Thompson, 2005: 2).

Toca turno de examinar lo que se refiere al apoyo diplomático. Este es

9 Para mayor referencia sobre la condicionalidad para otorgar AOD, véase: Prado Lallande (2006) una de las herramientas más fuertes que ejerce el poder suave, de acuerdo con Melissen (2005). Vuving se refiere a este instrumento cuando se identifican las acciones diplomáticas de un actor hacia otro en apoyo a determinada decisión o acción; cita el ejemplo (que bien sirve para nuestra investigación) de que el principio chino de la no intervención en asuntos internos produce una atracción evidente que le permite incursionar en el mercado de los recursos naturales, tan necesitados por el gigante asiático (énfasis y repitiendo, en África).

En el caso de la Ue, el encargado de tomar decisiones de política exterior es el Consejo Europeo (en el marco de la PESC), mientras que la institución que se encarga de ejecutarla es la Comisión Europea (a través del servicio exterior). Así, la Unión cuenta con 155 delegaciones alrededor del mundo, de las cuales 144 son embajadas ante diversos países (se incluye la oficina de asuntos comerciales y culturales en Taiwán, las oficinas en el territorio palestino ocupado, la oficina en la franja de Gaza, en Kosovo, las oficinas de asuntos consulares y económicos en Hong Kong y Macao y la Delegación de la UE para el Pacífico), y 11 son misiones permanentes ante organismos internacionales (incluye las misión ante el Consejo de Europa en Estrasburgo).

Por su parte, China encarga la planeación y ejecución de su política exterior al Ministerio de Asuntos Exteriores; tiene en su haber 174 representaciones, de las cuales 164 son embajadas en países (incluye las oficinas en Kiribati 
y ante la Autoridad Nacional Palestina), y 10 son misiones permanentes ante organismos internacionales (incluyendo la oficina de desarrollo económico en Panamá, y en Haití y la embajada de China ante las Comunidades Europeas).

Con base en lo anterior se puede deducir que China tiene más presencia en el mundo que Europa. Ello obedece a la "gran estrategia diplomática", a la que ya citada en párrafos anteriores $\mathrm{y}$, sobre todo, a la complejidad en que incurre la UE para la formulación de su política exterior. Al ser un ejercicio comunitario, es difícil convenir en asuntos exteriores (sobre todo, tomando en cuenta la lenta institucionalización de la PESC), cuestión que no afecta a China dada la supremacía el Partido Comunista en asuntos políticos tanto internos como externos, lo que le permite un control más eficaz para un desarrollo más óptimo de sus relaciones internacionales. También es importante recalcar que se toma en cuenta solo la representación de la UE en su conjunto y no de los países que la conforman; de ser así, los países europeos sobrepasarían por mucho las representaciones chinas en el mundo, pero ello no otorga consistencia a la presencia de Europa como tal.

En el ejercicio del apoyo diplomático se pueden identificar instrumentos tanto de la ue como de China que facilitan el uso de esta herramienta de poder suave. En lo que a la UE se refiere, dichas herramientas se plasman en el Tratado de la UE, el cual distingue tres: estrategia común, acción común y posición común (Barbé, 2005). En el periodo 2008-2009, la Unión implementó el ejercicio de cuatro posiciones comunes (2004/293/PEsC[2] y 2004/694/PESC [2], todas referentes al Tribunal Penal Internacional para la ex-Yugoslavia), se aplazaron cuatro posiciones comunes (para 2009, las vistas anteriormente) y se renovaron las medidas definitivas para la ejecución de un mandato para el Tribunal Penal Internacional para la ex-Yugoslavia (Consejo de la Unión Europea, 2009).

En el caso chino, toda su acción diplomática actual gira en torno al concepto confuciano de guanxi (compañerismo) (Bolewski y Rietig, 2008), el cual fomenta de manera especialmente bilateral con las grandes potencias a fin de asegurar que no existan amenazas a su "desarrollo pacífico". Se puede apreciar una jerarquía que va desde la "alianza estratégica», hasta la «sociedad estratégica», aunque en este existen matices dadas las peculiaridades que China tenga con el resto de los países con los que entabla este tipo de relaciones: "sociedad completa y a largo plazo» con Francia; "sociedad completa y cooperativa» con Reino Unido; "sociedad de confianza» con Alemania; "sociedad estable, de largo plazo y constructiva» con Estados Unidos; "sociedad amistosa y cooperativa» con Japón, etc. (Goldstein, 2001). Aunado a lo anterior, se establecen dichas sociedades con un marcado carácter económico-comercial, aunque también las hay de carácter político y 
Eduardo Tzili Apango • De la estrategia del encanto a la potencia civil...

hasta militar (como la Organización para la Cooperación de Shanghái).

Pero no solo son las acciones comunes lo que define la composición del apoyo diplomático. También las maniobras diplomáticas en torno al multilateralismo y a la cooperación (en el marco de la globalización) pueden precisar un despliegue de poder suave. En este sentido, se podría identificar la consolidación de regímenes internacionales como factor fundamental de la ejecución del poder antes mencionado, toda vez que se observa una demanda de los mismos, ya que se vinculan a la seguridad económica y regional, relacionadas a su vez con la necesidad de haber instrumentado el poder suave en primera instancia. En otras palabras, los regímenes internacionales son el reflejo de un nuevo orden mundial de naturaleza esencialmente económica, con base en el poder suave: "Lo regímenes son valiosos para los gobiernos cuando, en su ausencia, sería imposible consumar ciertos acuerdos mutuamente beneficiosos» (Keohane, 2005); se fomenta la cooperación.

Keohane afirma que virtualmente existen tantos regímenes internacionales como tipos de temáticas concurran en razón de los problemas que de ellas emanen. Se pueden observar con base en cuatro componentes distintos: principios, normas, reglas y procedimientos en la toma de decisiones. Se tomará en cuenta para puntualizar en qué tipo de regímenes ha incurrido tanto la UE como China, haciendo énfasis en el fomento de algún tipo de organización internacional a iniciativa de los dos actores antes mencionados, que aseguren la cooperación por encima del conflicto.

Para el caso de la uE, el caso inmediato anterior, la búsqueda del establecimiento de marcos regulatorios que promuevan la cooperación podría ser de naturaleza distinta al de China. En todo caso, la misma UE (y todas sus instituciones) son fiel reflejo de una estrecha cooperación entre sus 27 países miembros. Se tomarán aquellos organismos en que la UE tenga representación y que, además, se hayan originado por iniciativa de la misma (lo mismo se hará para el caso chino).

Así, la ue ha incurrido en la creación de regímenes de tipo político-militar (defensa), económico-financieros y comerciales principalmente. A continuación se ofrece una lista de ellos, enfatizando su naturaleza y su fin (ver el Cuadro 2)

Es visible que la uE promueve el establecimiento de ciertos regímenes destinados a custodiar su seguridad suave principalmente, aunque no por ello descuidan su seguridad fuerte (Barbé, 2000), esto en un carácter geopolítico cercano, lo que confirma, una vez más, que la prioridad de la UE es para con ella misma y sus regiones vecinas, sin ánimos de extender sus acciones y/o influencia a un nivel más global.

En materia de regímenes promovidos por la República Popular ver Cuadro 2. 
Estudios Internacionales I70 (20I I) • Universidad de Chile

\section{Cuadro 2. Regímenes con base en organizaciones internacionales promovidos por la UE}

\begin{tabular}{|c|c|}
\hline Regimen & Propósito \\
\hline PHARE & $\begin{array}{c}\text { Ayuda financiera a los esfuerzos de los países de Europa Central y Oriental a reformar y reconstruir } \\
\text { sus economías }\end{array}$ \\
\hline BERD & $\begin{array}{l}\text { Canalizar la ayuda financiera internacional a la reconstrucción de Europa Central y Oriental, exten- } \\
\text { diendo sus servicios en la actualidad hasta el Asia Central }\end{array}$ \\
\hline Programa TACIS & $\begin{array}{l}\text { Favorecer la transición hacia una economía de mercado, y consolidar la democracia y el Estado de } \\
\text { derecho en los Estados socios de Europa Oriental y Asia Central, énfasis en la Federación Rusa }\end{array}$ \\
\hline OSCE & $\begin{array}{l}\text { Trabajo en la prevención del conflicto, manejo de crisis, peligro latente de violación a la seguridad, y } \\
\text { rehabilitación post-conflicto. Cuenta con la participación de muchos países no miembros de la UE, } \\
\text { como Estados Unidos, Japón, Israel y Georgia, entre otros }\end{array}$ \\
\hline AEM & $\begin{array}{l}\text { Iniciativa de cooperación e integración entre los quince miembros de la UE, y los doce países del sur y } \\
\text { este del mediterráneo (1995, Declaración de Barcelona) }\end{array}$ \\
\hline AELC & Área de Libre Comercio entre Islandia, Linchenstein, Noruega y Suiza \\
\hline EEE & $\begin{array}{c}\text { Acuerdo para promover un reforzamiento continuo y equilibrado de las relaciones comerciales y eco- } \\
\text { nómicas entre las Partes Contratantes, en igualdad de condiciones de competencia y en observancia de } \\
\text { unas normas comunes, con miras a crear un Espacio Económico Europeo homogéneo }\end{array}$ \\
\hline INTERREG & $\begin{array}{l}\text { Aumentar la cohesión económica y social en la Unión Europea fomentando la cooperación transfron- } \\
\text { teriza, transnacional e interregional, así como el desarrollo equilibrado del territorio. Se presta una } \\
\text { especial atención a la colaboración entre las regiones ultraperiféricas y aquéllas situadas en las fronte- } \\
\text { ras externas de la Unión con los países candidatos a la adhesión. }\end{array}$ \\
\hline BEAC & Desarrollo económico y social en la región de Barents, que incluye a los países nórdicos, Rusia y la UE. \\
\hline
\end{tabular}

Fuente: Barbé (2000); Europa (2006); OSCE (2010) y Parlamento Europeo (1998)

Cuadro 3. Regimenes con base en organizaciones internacionales promovidos por China

\begin{tabular}{|c|c|}
\hline Regimen & Propósito \\
\hline $\begin{array}{l}\text { Foro de Beijing para } \\
\text { la Cooperación } \\
\text { China-África }\end{array}$ & $\begin{array}{c}\text { Espacio de diálogo político y económico para afianzar las relaciones entre China y países del } \\
\text { continente africano }\end{array}$ \\
\hline OCS & $\begin{array}{l}\text { Encargado de la seguridad militar en la región que comprende desde Moscú hasta Beijing, } \\
\text { pasando por los países del Asia Central. Se enfoca en el combate contra el terrorismo (funda- } \\
\text { mentalismo islámico) y el control de las fronteras }\end{array}$ \\
\hline Foro Boao & Promover la integración económica regional \\
\hline ALC China-ASEAN & $\begin{array}{c}\text { Promover la cooperación regional y la inversión mutua entre China y los diez países miem- } \\
\text { bros de la organización* }\end{array}$ \\
\hline $\begin{array}{l}\text { Foro de cooperación } \\
\text { China-LEA }\end{array}$ & $\begin{array}{l}\text { Promover relaciones políticas con base en el respeto mutuo, forjar vínculos comerciales y } \\
\text { económicos encauzados al desarrollo común y ampliar los intercambios culturales. }\end{array}$ \\
\hline
\end{tabular}

Fuente: Rosas (2007); Shambaugh (2005) y Boao Forum for Asia 
Eduardo Tzili Apango • De la estrategia del encanto a la potencia civil...

La Unión Europea cuenta con más organizaciones internacionales, que ha desarrollado para diversos fines. Sin embargo se puede visualizar que el alcance de las organizaciones promovidas por China es más global, aunque son menos. Asimismo, se identifica la tendencia de los regímenes «europeos» a tener carácter más político y de seguridad, así como de fomentar y reforzar las economías de libre mercado en sus espacios contiguos (es decir, relaciona el desarrollo económico con la seguridad fronteriza y política). Los regímenes «chinos», por su lado, son de carácter más económico y geopolítico, toda vez que China tiene presente asegurar valiosos recursos naturales.

\section{CONSIDERACIONES FINALES}

Definitivamente el ejercicio de poder suave entre los actores estudiados no es de la misma naturaleza: China despliega capacidades mayoritariamente económicas, influyendo con inversiones y acuerdos de naturaleza comercial, principalmente. La base de sus «asociaciones estratégicas» es fundamental para entender este principio porque si bien se complejizan a medida que se desarrolla la relación bilateral, el inicio parece ser de carácter económicocomercial.

Otro elemento importante del poder suave chino es el apoyo a los Institutos Confucio para establecerse en diversos países, aunado al gran número de becas del gobierno chino, que habla de un aprovechamiento de su "ascenso» como potencia para la enseñanza del mandarín. Inclusive se relaciona con el primer punto expresado ya que son notables las intenciones para aprenderlo y así emprender negocios con Beijing.

Por último, es de suponer que la razón por la cual China se consolida como actor que empieza a configurar las relaciones internacionales es su habilidad de utilizar su poder inteligente: el poder suave respaldado de un prestigio, respeto (o hasta temor) que le otorga el incremento de su poder duro, otorgándole prioridad al primero.

Por su parte, la Unión Europea hace uso de su poder suave en un sentido más político e incluso moral. La «cláusula democrática» atentamente solicitada a México para la firma del tratado de libre comercio y el embargo de armas a China son claros ejemplos. Lo anterior no quiere decir que en muchos casos no se observe un tipo de pragmatismo en la construcción de sus relaciones, ${ }^{10}$ pero se visualiza la tendencia a prevalecer lo primero.

Un elemento importante del poder suave europeo es su gran aportación a la AOD. Empero, como lo señalado anteriormente, también viene condicionada ya sea positiva o negativamente, pero no respaldada de un poder duro como el caso chino. Dicho sea en otras

10 El «mantenimiento» de los dictadores en el Magreb africano (algunos recién removidos del poder por efectos de las revoluciones de jazmines) para el abastecimiento del petróleo, control de sus fronteras cercanas, o acceso por el Canal de Suez, son buenos ejemplos de ello. 
palabras: la influencia europea está limitada por este importante factor, porque aun cuando condicione su ayu$\mathrm{da}$, poco puede hacer para configurar las relaciones internacionales en favor de sus principios morales. La «cláusula democrática» no volvió más democrático a México, ni evitó que China dejara de comprar armas.

Lo que sí se puede concluir es que hablar del poder suave como medio para triunfar en la política mundial es una falacia: China emerge con fuerza y empieza a modificar la naturaleza de las relaciones internacionales no por su poder suave, sino por su poder inteligente en consolidación. Los desajustes estructurales al interior de la UE ya no le permiten seguir construyendo su estatus de "potencia civil», que por sí misma no daba forma a la dinámica global y ni siquiera los intentos de edificar un poder inteligente (como el envío de tropas a Afganistán bajo bandera de la OTAN) han sido fructíferos.

El presente artículo compara dos casos de estudio sobre actores que tratan de adecuar su política exterior frente a la nueva realidad mundial del siglo XXI mediante el uso del poder suave. El éxito de su poder político global es relativo dada la divergente naturaleza de instrumentos utilizados para un fin determinado. Como se podrá observar, el poder duro aún sigue siendo importante (más no determinante) en la configuración de las relaciones internacionales y el Estado sigue siendo el actor principal de las mismas (aunque no el único). Como bien reconoce Nye en su más reciente obra, la suma de ambos poderes dará lugar a un poder inteligente, pero el mismo no se podrá utilizar a manos de que se efectúe una estrategia inteligente (2011: 207-217), factor que sí está logrando China, más no Europa.

La UE como actor supranacional se tambalea frente a las dificultades de la crisis económico-financiera que ha azotado al mundo desde 2008 y frente a ello China ha intentado salir a su rescate mediante la compra de deuda portuguesa y griega. Por su parte, China experimenta numeras revueltas civiles, muchas de ellas influidas por las «revoluciones de jazmines» en Medio Oriente, evidenciando fallas en el respeto a los derechos humanos, tan enfatizado por la Unión Europea.

Sin duda alguna tanto Bruselas como Beijing tienen mucho que hacer al interior de sus jurisdicciones, y es algo que el artículo no indagó lo suficiente: el poder suave desde el punto de vista interno, y es un campo abierto a la investigación: ¿qué influencia tiene el ámbito doméstico en la construcción de un poder suave?

Medir el éxito en la política global a partir del poder suave es incluso subjetivo. El éxito de un actor en el sistema global se calculará a partir de que la configuración que realice en las relaciones internacionales tenga beneficios mutuos entre los países y no entre sus élites. En ese sentido, la utilización del poder suave para adquirir un estatus deseado por China y la UE ha servido para fines políticos pero no para el 
Eduardo Tzili Apango • De la estrategia del encanto a la potencia civil...

bien global. Y es otro ámbito abierto a investigación ¿hasta qué punto el poder suave de las potencias ha servido para el desarrollo de aquéllas zonas impactadas por él? Se espera, pues, que el presente artículo de investigación haya servido para responder a las preguntas planteadas, así como para continuar el estudio del poder suave y el impacto de sus herramientas en la conformación de una dinámica global libre de conflictos.

\section{Hemerografía}

«2008 Annual report», China Scholarship Council Web Page (<http://www.csc.edu. cn/uploads/20090831162723653.pdf)>

«AG/46/182/1991, Resolución de Asamblea General, Naciones Unidas", Global Humanitarian Assistance (Disponible en: $<$ http://www.globalhumanitarianassistance.org/>)

«China continua 600 años de desarrollo pacífico", Spanish.News.cn (<http://spanish. news.cn/>)

«China's developing-country identity remains unchanged", Embassy of the People's Republic of China in the United States of America (<http://www.china-embassy.org $>$ )

«Education \& Trainning», European Commission (<http://ec.europa.eu>)

«El chino, idioma de moda en colegios de Estados Unidos», BBC Mundo (http:// www.bbc.co.uk/mundo)

«Erasmun Mundus Students, 2004-2009

Totals", Europe: Executive Agency. Education, Audiovisual \& Culture (<http:// ec.europa.eu/education/programmes/ mundus/projects_en.html>)

"Is China still a developing country?", People's Daily Online (<http://english. peopledaily.com.cn>)

«Missions overseas», Ministry of Foreign Affairs of the People's Republic of China (<http://www.fmprc.gov.cn/>)
"Peacekeeping Operations of the EU members", Barcelona Centre for International Affairs СIDОВ (<www.cidob.org/en/ >)

«Taking Europe to the World. 50 years of the European commission's external service» (2004), Europe (<http://eeas.europa.eu/>)

«Tratados y Legislación», Europa (<http://europa.eu/abc/treaties/index_es.htm\#coal>)

\section{Bibliografía}

BArbé, E. (2005), «La Unión Europea en el mundo: entre el poder de transformación y los límites de la Constitución», Real Instituto Elcano de Estudios Internacionales y Estratégicos, 2005 (Disponible en: <Almendron.com, http://www.almendron.com/politica/pdf/2005/europa/ europa_0607.pdf $>$ )

Barbé, E. (Coord.) (2000), Politica Exterior Europea, Editorial Ariel S.A., España

Bijian, Z. (2005) «China's 'Peaceful Rise' to Great.Power Status» en Foreign Affairs, Vol. 84, No. 5, Estados Unidos

Binder, A. y Conrad, B. (2009), "China's potential role in humanitarian assistance», Humanitarian Policy Papers, (Disponible en: Global Public Policy Institute, <http:// www.gppi.net/fileadmin/gppi/Binder_Conrad_2009_CHN_in_Hum_Assis.pdf $>$ )

Broom, E. V. (2003), «Perception of the danger: The China Threat Theory», Journal of Contemporary China, Vol. 12, Issue 35

Bustelo, P. (2005), «El Auge de China: ¿amenaza o 'ascenso pacífico'?», ARI No. 135/2005, Real Instituto Elcano de Estudios Internacionales y Estratégicos (Disponible en: eCentro de Innovación y Colaboración Universitaria <http://elac. uca.edu.ni/pd/economia/files/75/251/Pa $\mathrm{blo}+$ Bustelo $+2005+\mathrm{El}+\mathrm{ascenso}+\mathrm{de}+\mathrm{Chi}$ na.pdf $>$ )

Cortazar, J. y Marcos, F. R. (s/a), «La financiación de la asistencia humanitaria: el papel de los donantes y sus implicaciones", Universidad Complutense de Madrid: 
Biblioteca (http://www.ucm.es/info/IUDC/ img/biblioteca/9-REY_Financiacin.pdf)

Ferrero-Waldner, B. (2007), "The European Union and the world: a hard look at soft power», European Comissioner for External Relations and European Neighbourhood Policy, Speech/07/576, Columbia University (<europa.eu/rapid/pressReleasesAction.do? reference=SPEECH $>$ )

Fox, J. y Godement, F. (2009), «A power audit of EU-China relations", Policy Report, European Council of Foreign Relations, (Disponible en: <http://ecfr.3cdn. net/532cd91d0b5c9699ad_ozm6b9bz4. pdf $>$ )

Huacuja Acevedo, L. A. (2010), Reunión de la Comisión Parlamentaria Mixta México-Unión Europea 2010. Cuaderno de Trabajo. UNAM Fes Acatlán, México D.F. (Disponible en: <http://www.peceacatlan.com/Cuadernos \%20de\%20trabajo/ CUADERNO \%20FINAL \%20XI\%20 REUNION\%20PM\%20MEXUE\% 20 (web).pdf $>$ )

KurlantzicK, J. (2007), "Charm offensive: how China's soft power is transforming the world", Washington Journal of Modern China, Foreign Policy Research Institute, Estados Unidos

Lum, T. (2009), "China's assistance and government-sponsored investment activities in Africa, Latin America, and Southeast Asia», Congressional Research Service Report, Estados Unidos (Disponible en: <http://www.fas.org/sgp/crs/row/R40940. $\mathrm{pdf}>$ )

Maldonado, C. E. (2005), «La lógica del multilateralismo: una red dinámica compleja", Oasis Documentos, No. 10, Colombia (Disponible en: REDALYC, <http://redalyc. uaemex.mx/pdf/531/53101012.pdf >)

Melissen, J. (2005), «Wielding soft power: the new public diplomacy», Clingendael Diplomacy Papers, no. 2, Netherlands Institute of International Relations, (Disponible en: <http://www.nbiz.nl/ publications/2005/20050500_cdsp_paper_diplomacy_2_melissen.pdf $>$ )
Nossel, S. (2004), "Smart Power», Foreign Affairs, Vol. 82, Issue 2, Estados Unidos

Nye, J. S. Jr. (1990), «Soft Power», Foreign Policy, Estados Unidos

NyE, J. S. Jr. (2006), "Think again: Soft Power", Foreign Policy, Estados Unidos

NyE, J. S. Jr. (2011), The future of power, Nueva York, Public Affairs

Prado Lallande, J. P. (2006), «La condicionalidad política de la Cooperación al desarrollo: las sanciones a la ayuda internacional», Universidad Complutense de Madrid, Tesis doctoral, España (Disponible en: <http://eprints.ucm.es/tesis/cps/ ucm-t28973.pdf $>$ )

Prado Lallande, J. P. (2010), «La cooperación internacional para el desarrollo Unión Europea-México: Acciones, Logros y Retos», en Huacuja Acevedo, L. A., Reunión de la Comisión Parlamentaria Mixta México-Unión Europea 2010. Cuaderno de Trabajo. UNAM Fes Acatlán, 2010. 82 (Disponible en: <http://www.peceacatlan. com/Cuadernos \% 20de \% 20trabajo/ CUADERNO \%20FINAL \%20XI\%20 REUNION\%20PM\%20MEXUE\%20 (web).pdf $>$ )

Rosas, M. C. (2007), China en el siglo XXI: ¿hacia una nueva bipolaridad?, Universidad Nacional Autónoma de México y Australian National University, México

Sanahuja, J. A. (2004), "Los dilemas de la política de desarrollo de la Unión Europea», Anuario P2015, España (Disponible en: Federación de ONG de Desarrollo de la Comunidad de Madrid, http://www. fongdcam.org/manuales/educaciondesarrollo/datos/docs/A_docs/5_5_Dilemas\%20UE.pdf)

Scott, D. (2007), "China and the EU: A strategic Axis for the Twenty-First Century?» International Relations, Sage Publications, Memorial Institute for International Studies (Disponible en: http://ire.sagepub. com)

Smith, K. E. (2000), "The end of civilian power EU: A welcome demise or cause of concern?» The international spectator, Volume XXXV, No. 2, 2000 
Eduardo Tzili Apango • De la estrategia del encanto a la potencia civil...

Smith, K. E. (2005), "Still 'civilian power EU'?» European Foreign Policy Unit Working Paper, Det samfunnsvitenskapelige fakultet, 2005, (Disponible en: <http:// www.sv.uio.no/arena/english/research/ projects/cidel/old/WorkshopOsloSecurity/ Smith.pdf $>$ )

Thompson, D. (2005), «China's Soft Power in Africa: From the 'Beijing Consensus' to Health Diplomacy», China Brief, Vol. 5, Issue 21, (Disponible en: The JamesTown Foundation, <http://www.jamestown.org/>)

Toro Hardy, A. (2010), «China: poder duro y poder suave. Desde comienzos de este año su dureza ha comenzado a extenderse", El Universal, Venezuela (<http://www. eluniversal.com/>)

Vuving, A. L. (2009), «How Soft Power works», ponencia presentada en Soft Power and Smart Power, American Political Science Association annual meeting, Canadá

Whitman, R. G. (1997), «El futuro de la Unión Europea: ¿Poder civil o superpotencia?», Foro Internacional, No. XXXVII-3, Centro de Estudios Internacionales, El Colegio de México, México 